\title{
The Dance of the Sharp-tailed Grouse
}

\section{by Doug Gilroy, Regina}

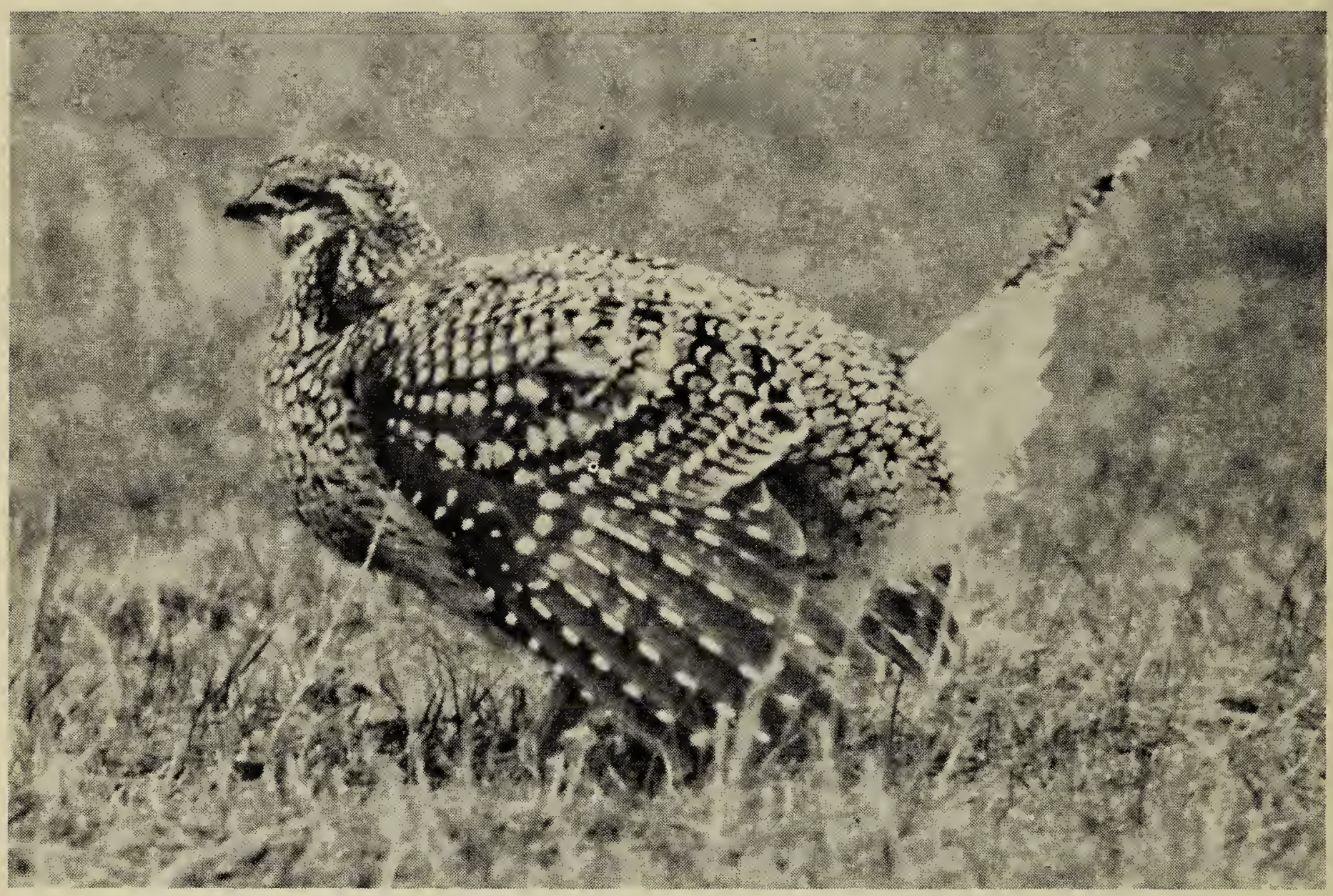

The age-old dance of the Sharp-tailed Grouse is one of the most stirring events of the prairie spring. On the remote piece of prairie where these pictures were taken 100 birds gathered an hour before daylight to perform their dancing ritual.

Only the cocks dance. The bird on the cover has been resting a few minutes and is now getting ready to dance again. In the picture above he is rapidly coming into the dancing pose, head extending forward, wings drooping and tail raised. In the picture below we see the cock in typical dancing pose. The purple air sacs on the side of his neck are extended, and with feet that stamp so fast they are only a blur, he glides about like a mechanical toy.

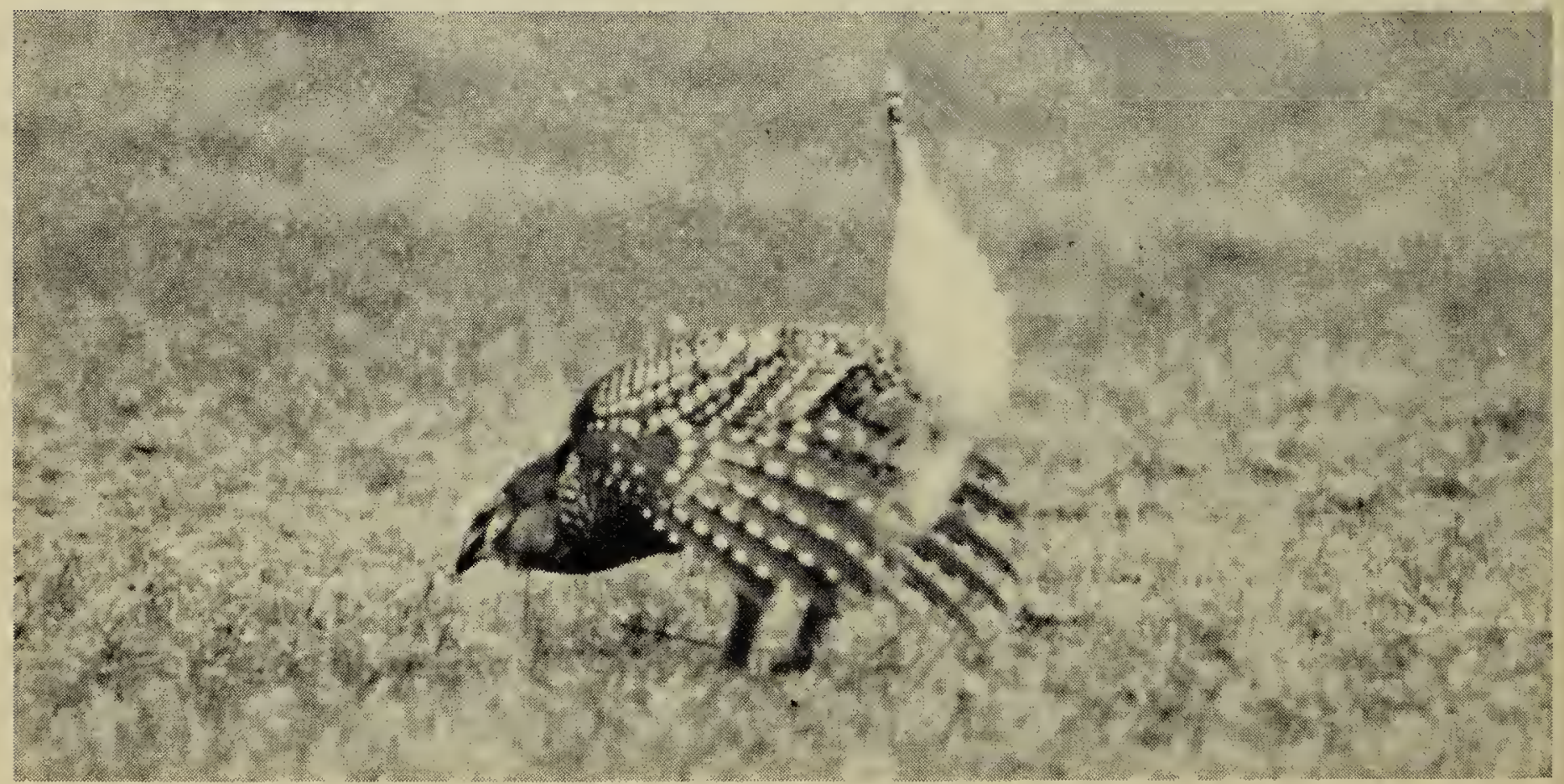




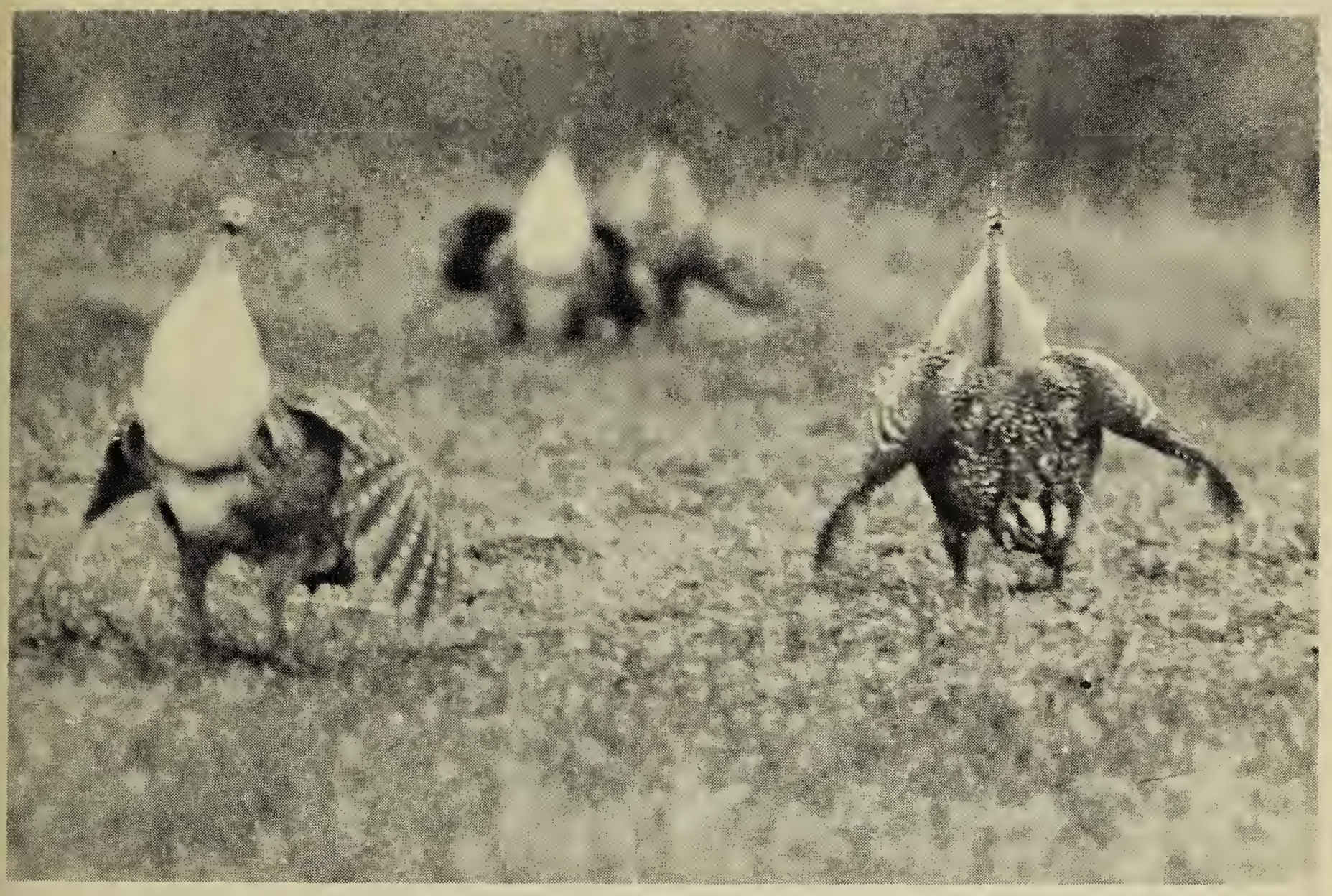

Each bird has a partner (as seen in the above picture) and they bow and gyrate around each other with all the vigour of human jitter bugs. In the last photo a round of the dance is about to conclude. Each bows politely to his partner; then, still facing each other, they simply go into a squat, in which position they rest a few minutes. Suddenly as if a signal has been given, all leap to their feet and the dancing begins all over again.. With 100 pairs of feet going at once, the ground fairly rattles.

As the sun slowly rises over the eastern horizon the fever of the dance stops almost immediately. A few die-hards may keep going, but the dance is really finished for another day.

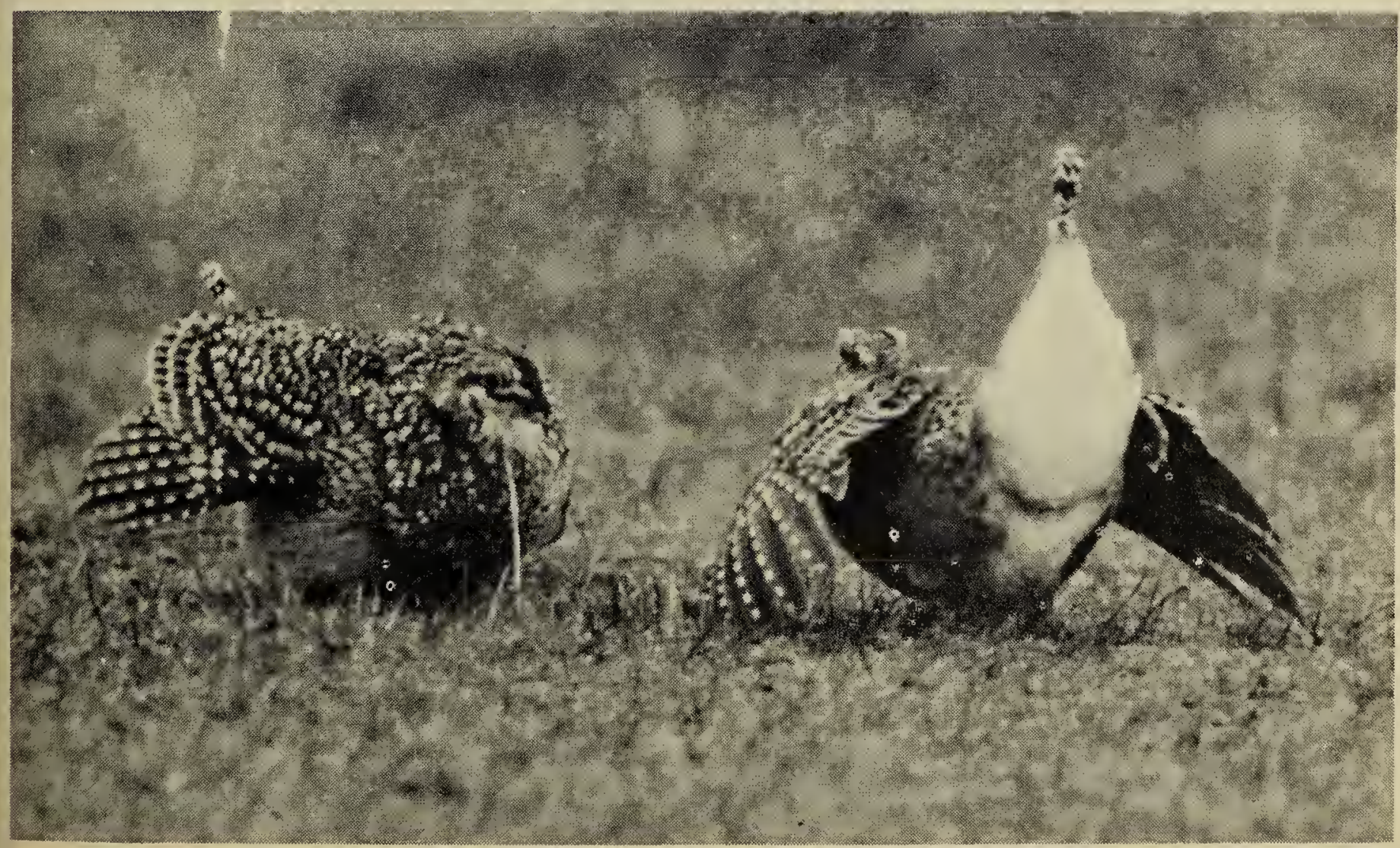

